\title{
Design and Implementation of Integrated Information Technology on SME Coconut Oil in North Sulawesi of Indonesia
}

\author{
Marike A. S. Kondoj \\ Department of Electrical Engineering \\ Manado State Polytechnic
}

\author{
Herry S. Langi \\ Department of Electrical Engineering \\ Manado State Polytechnic
}

\begin{abstract}
The study aims to develop a model of integrated information system that can be used to support the business processes of Small to Medium Enterprise (SME) coconut oil production in North Sulawesi. The proposed system development using Rational Unified Process (RUI) with laboratory test. The results indicates that in developing a business, then the SME needs a tool in the field of information technology to control the amount of oil production adjusted for the orders number from customers; therefore all available resources can be put together in order to bring benefits to the business operation
\end{abstract}

\section{Keywords}

Integrated systems, information systems, SME, RUI, coconut oil

\section{INTRODUCTION}

The cooperation unit business and small to medium enterprise (SME) have contributed of $6.31 \%$ economic growth of North Sulawesi. Moreover, the significant economic growth has triggered the much more small business units where the number of cooperatives unit business in North Sulawesi has reached 6,066 units with business volume has reached about US $\$ 100 \mathrm{M}$ by the end of 2015 with workforce absorption 10,515 people. Meanwhile, the numbers of SME are 69,853 units which comprises of 48,772 units of micro-enterprises, small business enterprises of 19,139 units and medium-sized businesses enterprises of 1,942 units with total assets reached US $\$ 500 \mathrm{M}$ and total turnover of US $\$ 900 \mathrm{M}$ trillion and able to provide employment to 171,436 people (www.metromanado.co.id, 2017).

Coconut oil is one of the processed coconut products that are considered able to contribute to the economy growth of North Sulawesi (Kaunang, 2013). Coconut oil has been continues as one of the excellent commodities in North Sulawesi with becoming the topped leading commodity exports amongst other products Nevertheless, the farmers rely only on coconut copra production and it is sold to collectors. So the farmers income is only focused on copra sale. In fact, the farmers can produce their own white coconut oil from their owned coconut or buying coconut from other farmers. When farmers may produce oil, it means that farmers can benefit more than just making copra and they could open up the jobs for the community.

Opportunities to profit from making coconut oil is very high. It is due to the coconut oil has proved to be useful also for health and began much sought after proven to solve many health problems. The opportunities come to the SME in North Sulawesi to produce high quality of coconut oil, which is proved much healthier than palm oil. For this reason, good controls and management is required to support the production of cooking coconut oil in order to meet the demand for coconut oil.

Regarding to the production planning, control and integrations, the productivity can be performed by having a production schedule to anticipate demand, the allocation of raw materials and labors which require good planning (Sipper \& Bulfin, 1997). Likewise with cooking coconut oil production in addition to the knowledge of how to produce good coconut oil, the business people or small and medium business entrepreneurs also requires knowledge of how to meet the demand for cooking coconut oil of consumers where the trend demand is continues to grow in the next 6 months to 1 year periods. Regarding to these problems, good production should follows good planning and controls for the efficient and effective usage of raw materials and labor costs (Bedworth \& Bailey, 1987).

The province of North Sulawesi has good potential to conduct the business production of coconut oil in high scale. However, the problems come with the number coconut oil entrepreneurs in North Sulawesi is still slightly even decreases due to the variety of oil production available in the market at an affordable price. In fact, by the 30 customers respondents in the city of Manado, the 22 of respondents still prefer to use cooking coconut oil but they are hampered on how to get it. Meanwhile, the coconut oil production in North Sulawesi as many as 277,719 tones per year. These data still open opportunities to produce cooking coconut oil on small and medium-scale industries to support the very high in the local market and to meet the demand for exports. For these reasons, it is important to design a tool model based information technology to support the coconut oil industry on small and medium enterprises in North Sulawesi (Kaunang, 2013).

Currently, the manufactures of cooking coconut oil in North Sulawesi has already utilized information system technology, but their system has not yet been integrated. In fact, if they use the information system technology optimally, they can improve productivity and competitive advantage of the company and including their products. The additional computerized system may assist the productivity process of cooking oil products in order to avoid scarcity of raw materials. In this respect, the order process regarding the product sale and receipt will streamlined as well as smooth coordinated in goods delivery. For these reasons, the research will be directed in designing of information technology systems by means a software product that can be implemented to help the SME for the increasing coconut oil productivity in North Sulawesi.

\section{CONFIGURATION OF PROPOSED SYSTEM}

2.1 Research Methodology

The utilized method for system development is the 
method of rational unified process (RUP). The system development of RUP follows iteratively (repeating) process and incremental (gradual with progress upward) process (Jogiyanto, 2005). It has four phases as follows that is conducted in sequential and iterative process where each iteration can be used to improve the next iteration.

1. Inception (preliminary) is the stage to model the required business processes and to define the need for the system to be proposed.

2. Elaboration (extension/planning) is the stage which is more focused on the planning of system architecture. The stage can also be made to determine whether the desired system architecture can be made or not. This stage emphazies the analysis of the system design and implementation. Also, the expected results of this phase is to fulfill the Lifecycle Architecture Milestone (boundary/ architectural milestones of the cycle).

3. Construction is the stage which is more focused on the component development of system or system features.

4. Transition is the stage is to elaborate the system design by the deployment or system installation in order to be users friendly. Activities at this stage includes in user training, maintenance and testing of the system according to meet the user expectations.

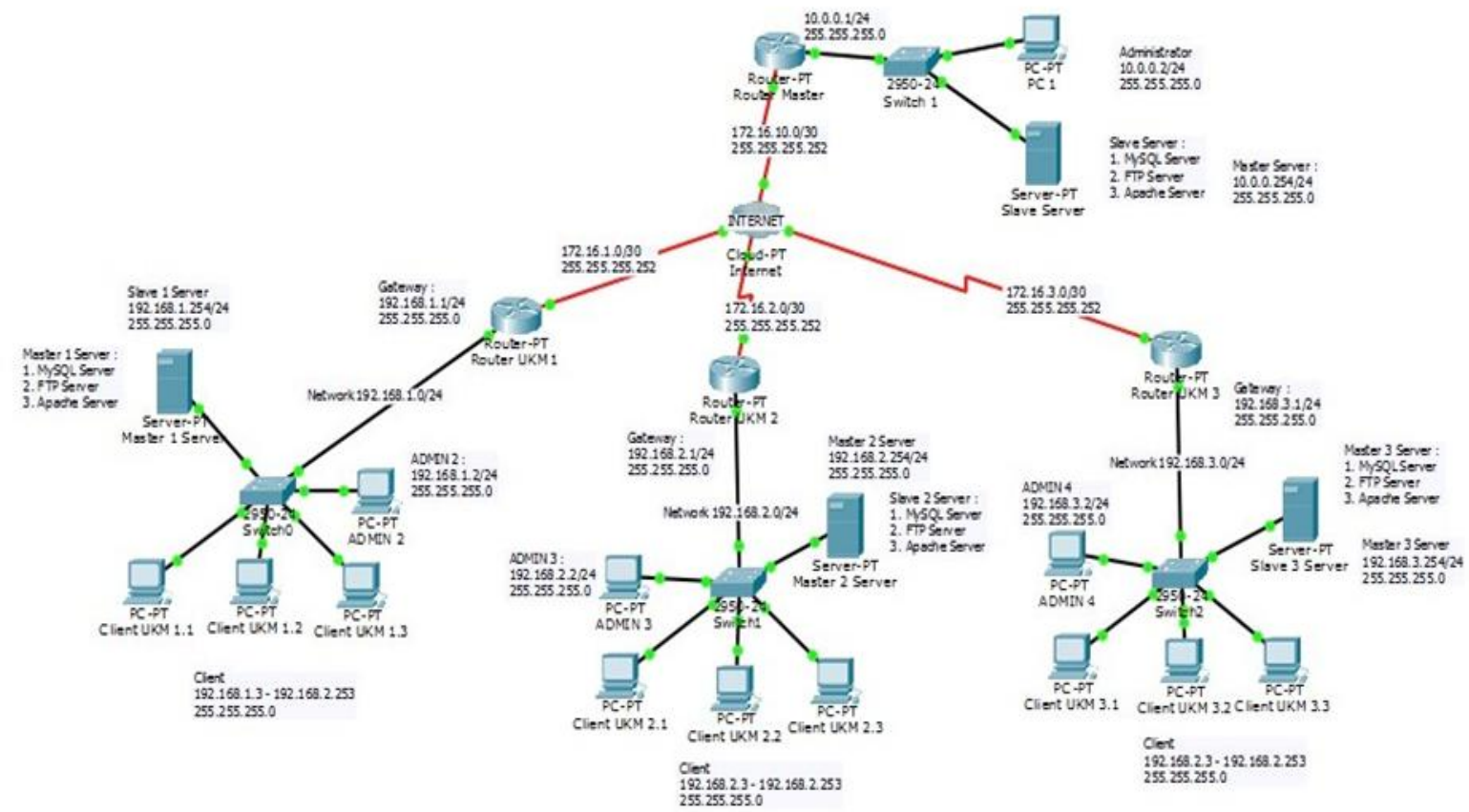

Fig. 1 Design of integrated network model of SME

\subsection{Design of Network Connectivity between SME}

Based on the previous research where the viability of the coconut oil business is promising, the research will focus on software development by means of the integration of SME in North Sulawesi through web network. The model of integrated network model that will be developed can be seen in Figure 1 as follows. The network concept where several networks of SME have their respective data storage. By utilizing the internet, each data storage among the SME can be integrated so that the resources that exist in every SME can be accessed by other SMEs. To maintain the availability or continuity of service to consumers, the SMEs should cooperate with each other in terms of the coconut oil availability, so that any existing orders from customers can be served in accordance with the time desired by consumers. Each SME has their owned internet network administrators.

\section{RESULTS OF ANALYSIS \\ COMPONENTS AND DISCUSSION}

The function of replication process is to retrieve the lost information automatically in another database when the origin database is damaged or malfunctioning. The concept is a quite unique technological because all order and instruction that exist in a database will be stored in another database. When data loss occurs, the data is recovery quickly because the data is still stored neatly in another database. In this case, MySQL replication is required for data storage among SME in the form of slave database that allows data from every SME can be recorded in a database. In addition, each SME has the respective database; therefore the data in each of SME are not overlapped with one another. The server will record all existing data on SME through an integrated network. By utilizing MySQL replication, any data can be backed up securely without fearing of losing their data.

Flowchart - Based on the previous survey, it was found that the business process will be undertaken in some SMEs which are not yet integrated with the computerized system. Recently, the SME business for coconut oil has experienced a very slow growth. Therefore, it is necessary to do in-depth analysis to develop tools that can help SMEs in controlling the process of busines productivity. The points for analyzed productivity is starting from the input, process and output. The process will be carried out in sequence. Some parts will regulate the production process from raw material availability, booking process until the transactions that are recorded in the form of reports. The flowchart in Figure 2 describes the overall system process regarding the order and relationship between the process and instructions. 


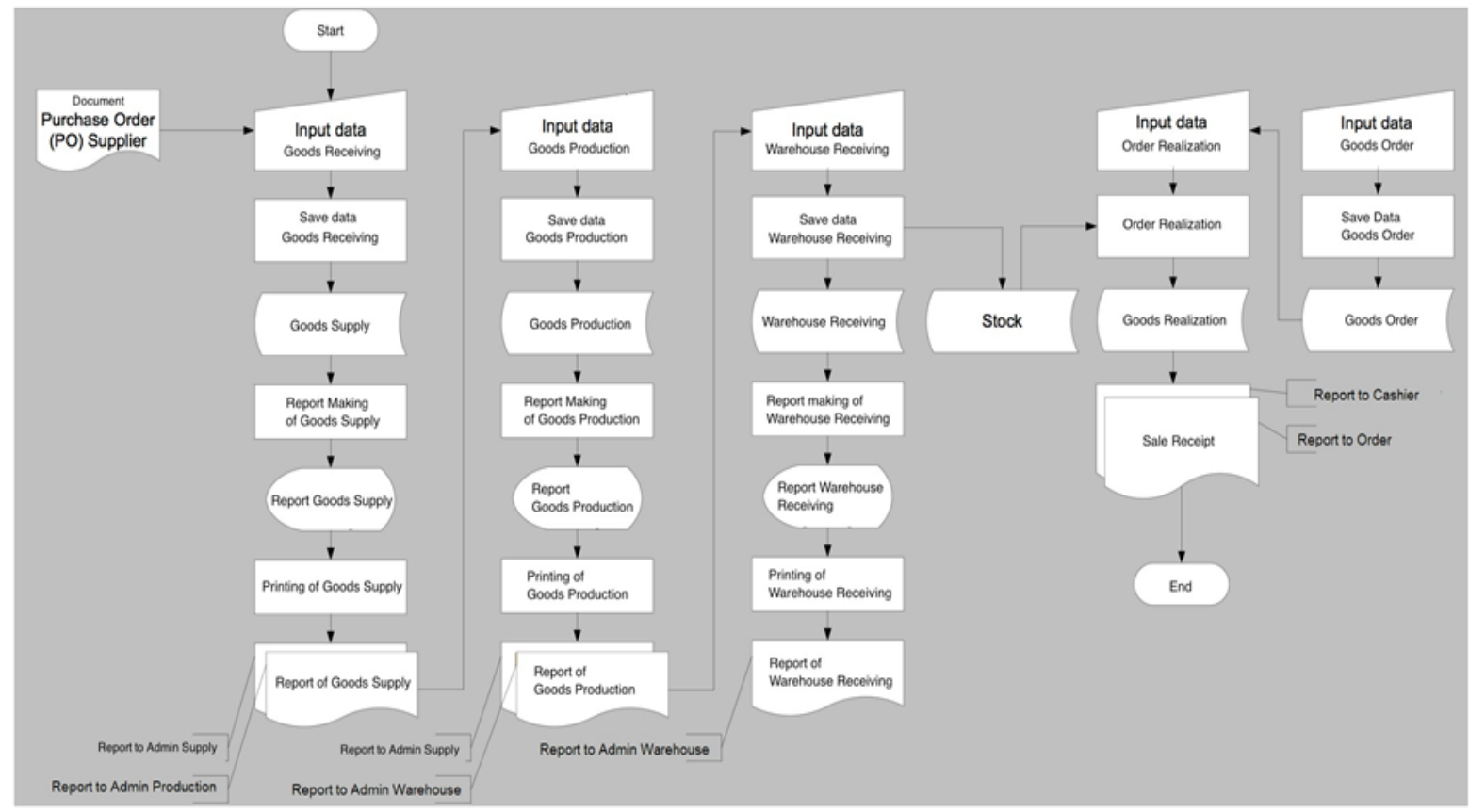

Fig. 2 System flowchart

Data Flow Diagram (DFD). DFD is designed for the analysis purposes and structurized to make it easier to understand the system and sub-system virtually as a series of interrelated data flow. The data flow diagram for system analysis is shown in
Figure 3. In this figure, the proposed system interacts with three related entities, i.e administrator, reservation and cashier.

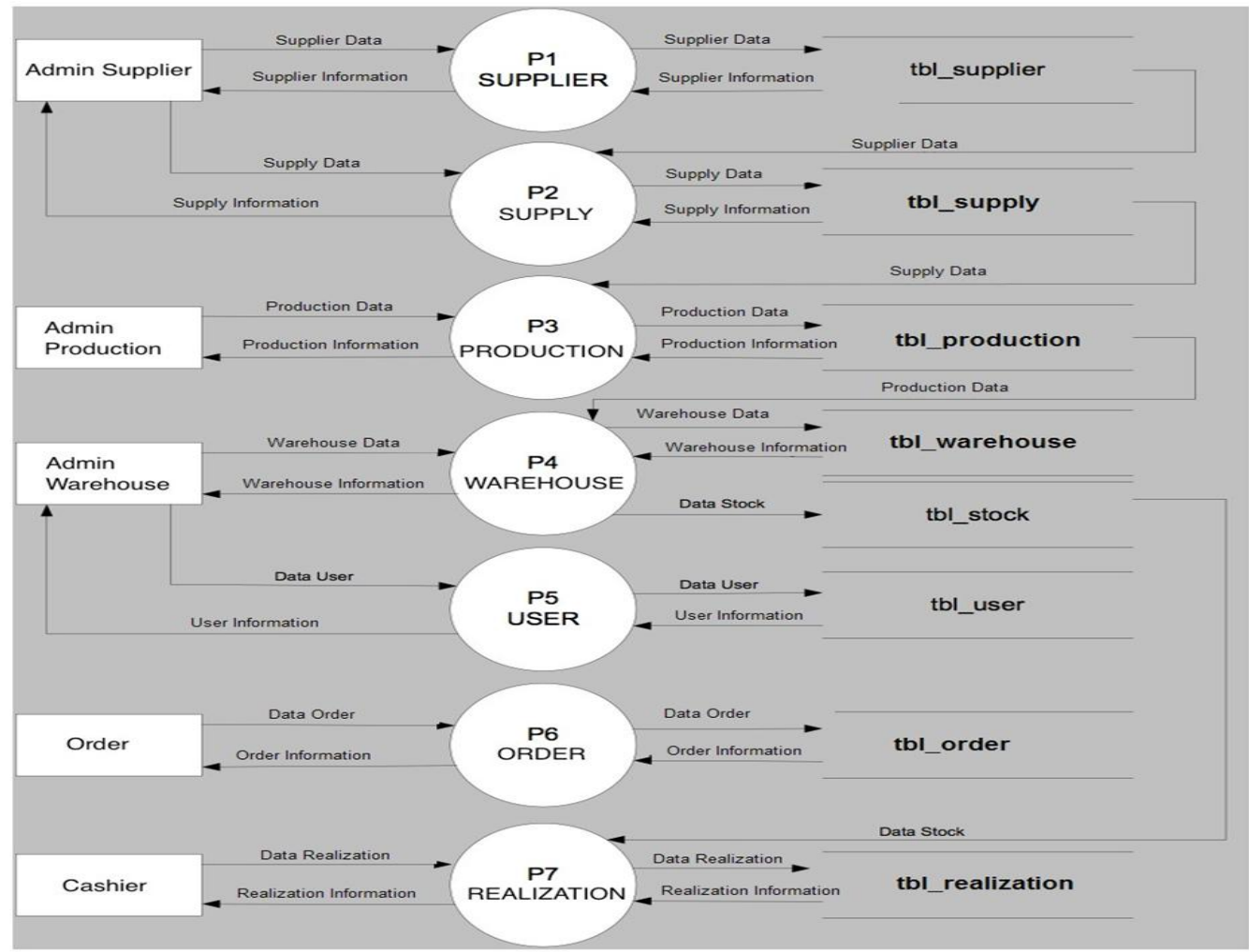

Fig. 3 Data Flow Diagram (DFD)

Design of Interface. An interface should be designed with a good visual display and ergonomics (Chen, 2015). In this case, the interface was developed based on the analysis that has been done on several previous description. Figure 4 as follows presents the developed user interface design of applications. It can be seen in this figure that the provided menu information are: Order, Cashier, Raw Material Supply, Production and Warehouse. Each part has designed with different login systems. 

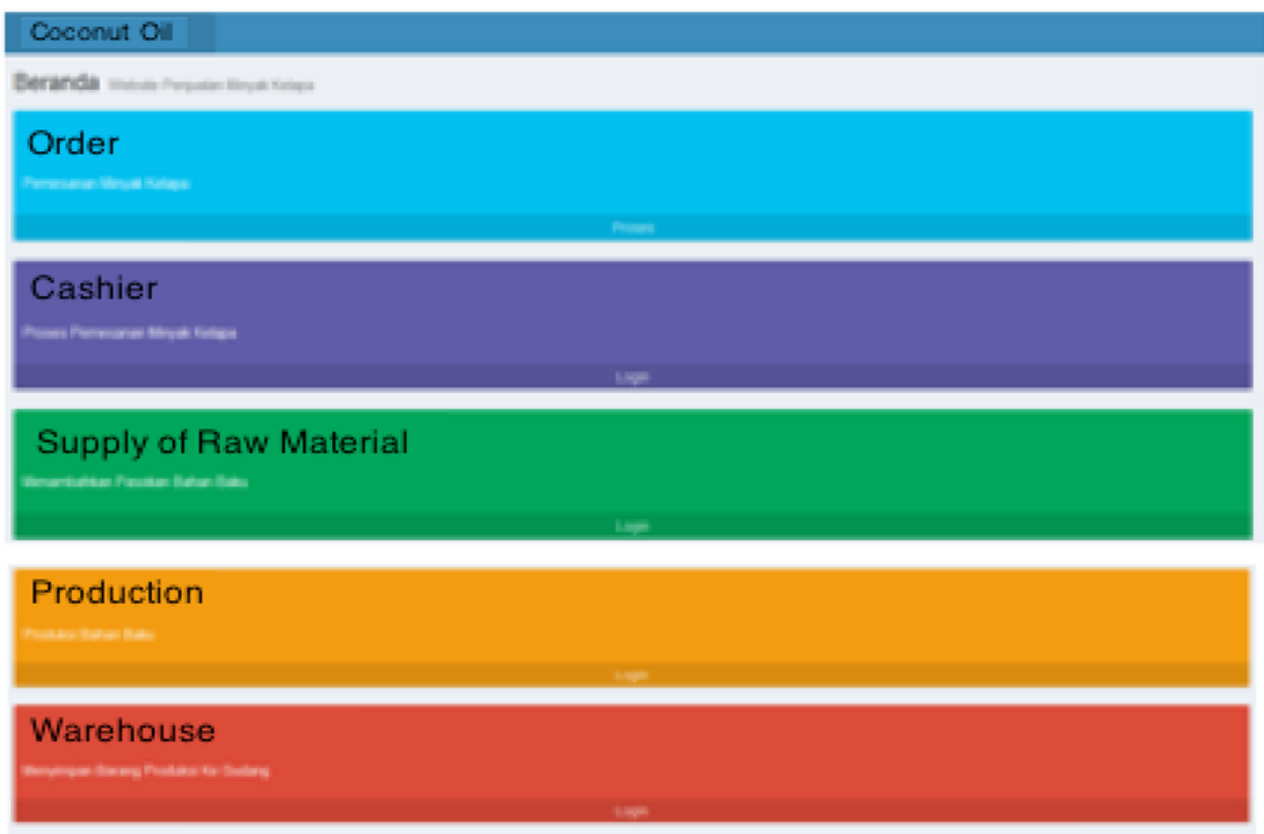

Fig. 4 Initial design of interface

The system is tested with black box and respondents tests. The testing results are presented as follows. The black box testing is presented in Table 1. Meanwhile, the respondent $\mathrm{s}$ test result is shown in Figure 5. In this case, the collection of data through questionnaires is carried out by providing a set of written questions to be answered by the respondents. The questionnaire type is a closed questionnaire where the answers are already provided, so that respondents can just choose and answer directly. With Likert scale of quality measures, there are four choices of possible answer, i.e very easy, easy, easy enough and is not easy.

Table 1. Black Box Testing

\begin{tabular}{|l|l|l|l|l|}
\hline No & Process design & \multicolumn{1}{|c|}{ Expected results } & Results & \multicolumn{1}{|c|}{$\begin{array}{c}\text { Additional } \\
\text { information }\end{array}$} \\
\hline 1 & $\begin{array}{l}\text { Administrator } \\
\text { login }\end{array}$ & $\begin{array}{l}\text { Administrators may do logging according to their } \\
\text { user name and pasword }\end{array}$ & $\begin{array}{l}\text { Working } \\
\text { properly }\end{array}$ & $\begin{array}{l}\text { If the input is } \\
\text { correct }\end{array}$ \\
\hline 2 & Order form & Saving data & $\begin{array}{l}\text { Working } \\
\text { properly }\end{array}$ & none \\
\hline 3 & Data process & Administrator may conduct data process & $\begin{array}{l}\text { Working } \\
\text { properly }\end{array}$ & none \\
\hline
\end{tabular}

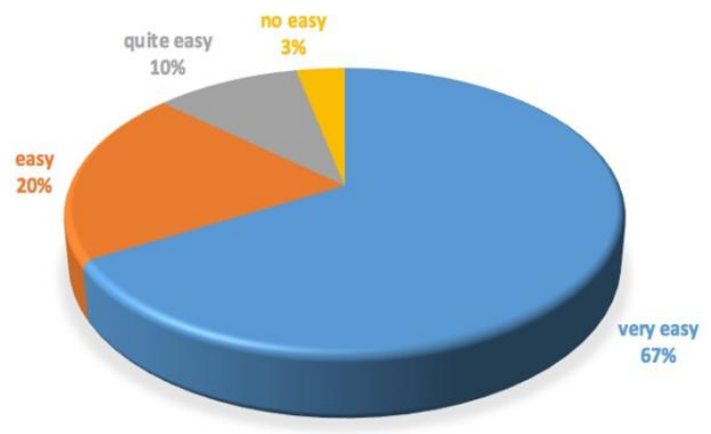

Fig. 5 Results of respondent test

\section{CONCLUSION}

The proposed integrated network system model is developed in accordance with existing business processes of SME coconut oil in North Sulawesi. The model is able to present the required information required by the SME in the control of raw materials, to avoid excess or shortage of raw materials and to serve consumers in well ordering. By developing an integrated network model, it allows multiple SMEs to work together in terms of consumer demand service in large numbers. With an integrated network model, the data security is well-maintained. The testing results indicate that the proposed integrate network model of SME coconut oil in North Sulawesi can be succesfully implemented. This system 
can be expanded again by providing various needs in terms of financial management.

\section{REFERENCES}

[1] http://www.metromanado.co.id/2016/01/koprasi-ukmsulut-dongkrak-pertumbuhan.html, accessed on 17 March 2017

[2] Kaunang W. (2013). In English: Competetiveness of export commodity of Coconut Oil in North Sulawesi. JurnalEmba 1315 Vol.1 No.4 Desember 2013

[3] Sipper \&Bulfin Jr., (1997). Production Planning, Control, and Integrations. McGraw Hill Bedworth D.D., Bailey
J.E., (1987). Integrated Production Control System, John Wiley \& Sons.

[4] Jogiyanto., (2005). In English: Analysis and Design of Information Systems. Penerbit Andi, Jakarta

[5] Chen Q, (2015). Compare and study about owing to the three kinds important softwaresdevelop process", Proceeding of the International Conference on Education Technology and Economic Management (ICETEM). 450-451. 2015 